\title{
Cold fronts in the Colombian Caribbean Sea and their relationship to extreme wave events
}

\author{
J. C. Ortiz-Royero ${ }^{1}$, L. J. Otero ${ }^{1}$, J. C. Restrepo ${ }^{1}$, J. Ruiz ${ }^{1}$, and M. Cadena ${ }^{2}$ \\ ${ }^{1}$ Applied Physics Group - Ocean and Atmosphere Area - Physics Department, Universidad del Norte, Barranquilla, Colombia \\ ${ }^{2}$ Meteorology Branch, Instituto de Hidrología, Meteorología y Estudios Ambientales de Colombia (IDEAM), \\ Bogotá D.C., Colombia
}

Correspondence to: J. C. Ortiz-Royero (jortiz@uninorte.edu.co)

Received: 3 April 2013 - Published in Nat. Hazards Earth Syst. Sci. Discuss.: 29 July 2013

Revised: 8 October 2013 - Accepted: 11 October 2013 - Published: 7 November 2013

\begin{abstract}
Extreme ocean waves in the Caribbean Sea are commonly related to the effects of storms and hurricanes during the months of June through November. The collapse of $200 \mathrm{~m}$ of the Puerto Colombia pier in March 2009 revealed the effects of meteorological phenomena other than storms and hurricanes that may be influencing the extreme wave regime in the Colombian Caribbean. The marked seasonality of these atmospheric fronts was established by analyzing the meteorological-marine reports of the Instituto de Hidrología, Meteorología y Estudios Ambientales of Colombia (IDEAM, based on its initials in Spanish) and the Centro de Investigación en Oceanografía y Meteorología of Colombia (CIOH, based on its initials in Spanish) during the last $16 \mathrm{yr}$. The highest number of cold fronts was observed during the months of January, February, and March, with 6 fronts occurring per year. An annual trend was observed and the highest number of fronts occurred in 2010 (20 in total); moreover, an annual strong relationship between the maximum average wave values and the cold fronts in the central zone of the Colombian Caribbean during the first three months of the year was established. In addition, the maximum values of the significant height produced by the passage of cold fronts during the last $16 \mathrm{yr}$ were identified.

Although the Colombian Caribbean has been affected by storms and hurricanes in the past, this research allows us to conclude that there is a strong relationship between cold fronts and the largest waves in the Colombian Caribbean during the last $16 \mathrm{yr}$, which have caused damage to coastal infrastructure. We verified that the passage of a cold front corresponded to the most significant extreme wave event of the last two decades in the Colombian Caribbean, which caused
\end{abstract}

the structural collapse of the Puerto Colombia pier, located near the city of Barranquilla, between 5 and 10 March 2009. This information is invaluable when evaluating average and extreme wave regimes for the purpose of informing the design of structures in this region of the Caribbean.

\section{Introduction}

According to Ortiz et al. (2012), the most important meteorological-marine event of the last $10 \mathrm{yr}$ along the Colombian coast was the passage of a cold front between 5 and 9 March 2009. The waves generated by this atmospheric front reached as high as $2.4 \mathrm{~m}$ in significant height and led to the collapse of a $200 \mathrm{~m}$ section of the Puerto Colombia pier, located on the Caribbean coast of Colombia.

Extreme ocean waves are typically related to the effects of storms and hurricanes, and according to Ortiz (2012), the two areas of the Colombian Caribbean that are most vulnerable to the threat of hurricanes are the island of San Andrés (zone 1 in Fig. 1), followed by the Guajira Peninsula (zone 2 in Fig. 1). However, reports of large waves are recorded in the marine-weather bulletins of the Oceanographic and Hydrographic Research Center $(\mathrm{CIOH}$, based on its initials in Spanish) of the Colombian Navy and the Institute of Hydrology, Meteorology and Environmental Studies of Colombia (IDEAM, based on its initials in Spanish) during months other than those of the hurricane season (June to November) on the Colombian Caribbean mainland. Thus, the question regarding the cause of these extreme wave events, which in 


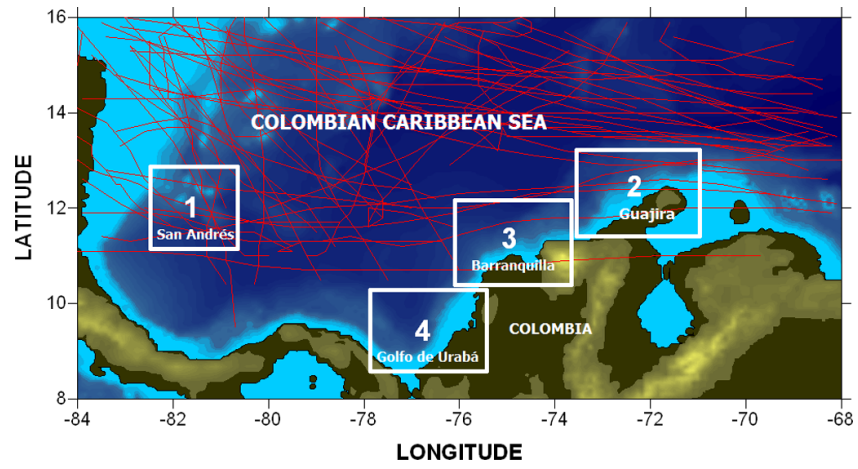

Fig. 1. Vulnerability of the Colombian Caribbean coast due to hurricanes (Ortiz, 2012).

certain cases have caused considerable damage to coastal infrastructure, is an important topic of interest.

Cold fronts are a category of so-called atmospheric fronts and are characterized as atmospheric disturbances produced by the collision of a cold air mass and a warm air mass. According to Thompson (1998), basically there are two types of fronts: cold and warm. Due to its geographical location, the Colombian Caribbean experiences cold fronts wherein air masses that are cooler than the hot air masses typical of the area move northward. When the dense and heavy air mass moves toward the warmer, lighter air mass, the cold air pushes the warm air upward at high speeds. Depending on the relative humidity, storm clouds may be formed, developing in a narrow band along the edge of the front and producing heavy rainfall (Fig. 2). In Fig. 2, $C_{\mathrm{b}}$ is the name of cumulonimbus clouds, $C_{\mathrm{i}}$ is the name of high-level clouds, $C_{\mathrm{s}}$ is stratocumulus and $A_{\mathrm{c}}$ is altocumulus clouds.

Cold fronts are air masses that have an approximately horizontal homogeneity in temperature and humidity. According to Namías (1960) and Mayhew (1997), air masses are areas of the atmosphere that extend for hundreds of kilometers and, in addition to exhibiting uniformity in temperature and humidity, have similar vertical variations in temperature and pressure.

The properties of currents created within an air mass depend on the region where the mass originated. If the air mass moves away from its original area, its properties tend to change. Such changes are readily observed in the lower layers, whereas the higher layers only gradually exhibit such variations (Namías, 1960). Cold fronts are of great importance in this study because they significantly affect the ocean-atmospheric conditions of areas that they cover. For example, cold fronts significantly increase the wind intensity, increase the cloud cover, decrease the temperature, increase the atmospheric pressure, and significantly increase the wave height. The last of these changes has the strongest effects on the Colombian Caribbean coast and the archipelago that includes the San Andrés and Providencia islands (CIOH).

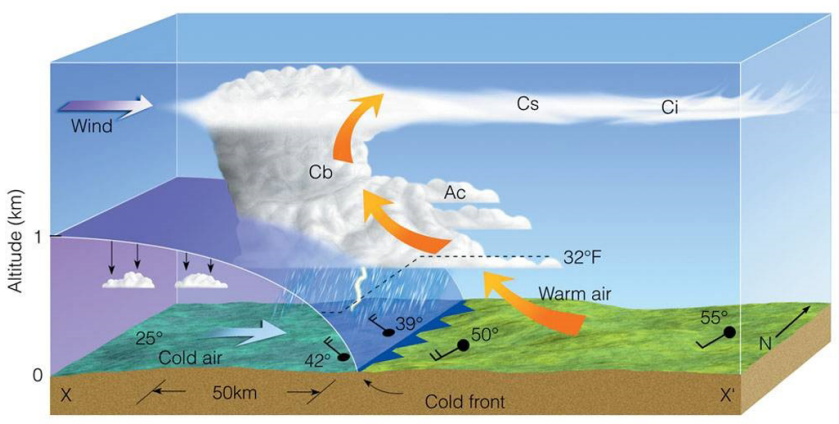

Fig. 2. Dynamics of cold fronts (Thompson, 1998).

Cold fronts, also called polar fronts, can reach low latitudes during the winter, thus affecting weather conditions in these areas. The intrusion of midlatitude cold air into the tropics occurs in various regions of the globe. These events are characterized by a pool of cold air in the middle latitudes, a strong pressure gradient in the lower troposphere, and the subsequent, abrupt intrusion of cold air into the tropics (Hastenrath, 1991).

Cold fronts are accompanied by heavy rainfall, causing floods and landslides. Increasing levels of atmospheric humidity and the likelihood that global warming will affect weather patterns suggest that similar climatic disruptions may become more frequent (Decibel et al., 2011). The relationships between the passage of cold fronts, sea level, and the exchange of currents within water bodies have been studied in Louisiana (Zhixuan and Chunyan, 2010). Other studies describe the effects of cold fronts elsewhere in the USA and in Australia (Locatelli et al., 1989; Beringer and Tepper, 2000).

A detailed study of the seasonality and frequency of cold fronts in the Colombian Caribbean has not been previously conducted. Narváez and Leon (2003) published one of the few studies on the impact of cold fronts in the Caribbean, in which they analyzed the intrusion of a cold front in January 2002. Figure 3 shows the intrusion of a cold front in the Caribbean Sea from the state of Arizona in the USA. These images correspond to infrared images of the GOES- 8 satellite $(10.2-11.2 \mu \mathrm{m})$ during 5 and 8 January 2002.

Ortiz et al. (2012) reconstructed the effect of waves generated by the passage of a cold front that brought down $200 \mathrm{~m}$ of the Puerto Colombia port infrastructure in March 2009. This work represents the first characterization of cold fronts along the Colombian Caribbean coast. This characterization was accomplished by the compilation of cold front events recorded during the last $16 \mathrm{yr}$, the establishment of their seasonality, and the use of trend analysis. 


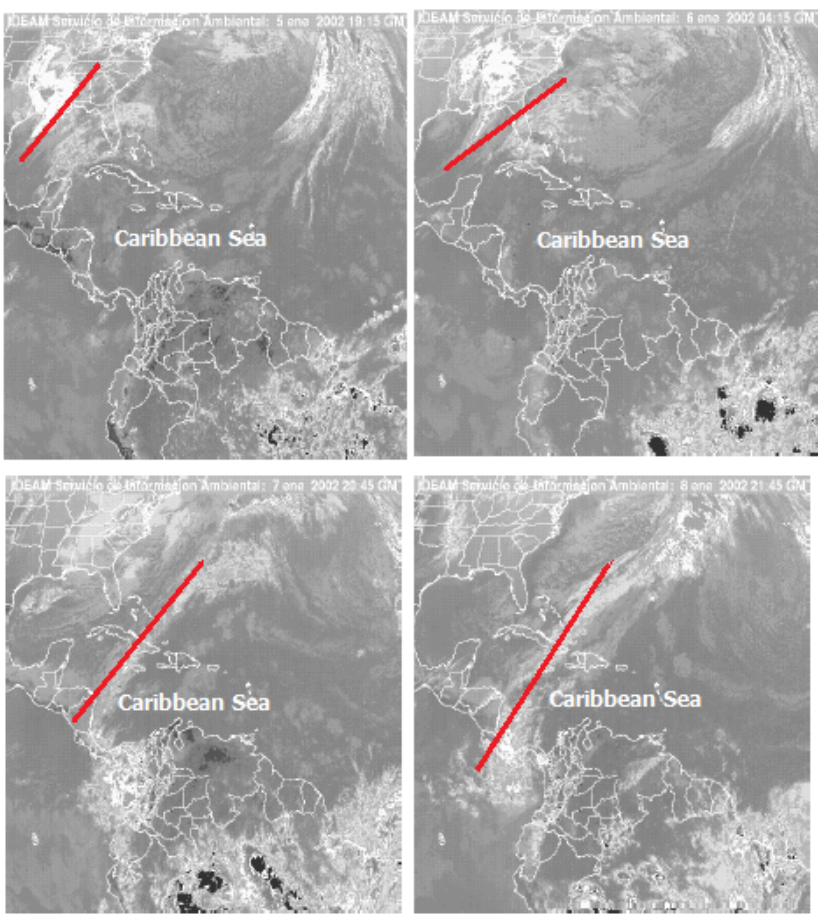

Fig. 3. Cold fronts in the Caribbean Sea in January 2002 (Narváez and León, 2003 and modified by the authors).

\section{Description of study area}

The surface area of the Colombian Caribbean is approximately $590000 \mathrm{~km}^{2}$. The Caribbean Sea is bounded by South America to the south, Central America to the west, the Lesser Antilles to the east, and the Greater Antilles (Cuba, Haiti, the Dominican Republic, and Puerto Rico) to the north. The Caribbean Sea is connected to the Gulf of Mexico by the Yucatan channel to the northwest and to the tropical Atlantic Ocean to the east. The Colombian Caribbean coast is approximately $1600 \mathrm{~km}$ long, and the main coastal cities in this important region are Riohacha, Santa Marta, Barranquilla, and Cartagena. A map of the Caribbean Sea is shown in Fig. 4.

The climate of Colombia's Caribbean coast is determined by its tropical location, which is exposed to direct solar radiation. Accordingly, there are no defined climatic seasons, in contrast to latitudes further from the Equator. In this region, there are two seasonal periods determined by precipitation and the patterns of the Aloysius winds of the east.

As shown in Fig. 5, the movements of the Intertropical Convergence Zone (ITCZ) produce three main seasons in Colombia: a dry period with strong winds (December-April), a transitional period (May-July), and a rainy period (AugustNovember). These three climatic periods may change both in duration and intensity due to the influence of the American monsoon system, low-level atmospheric wind currents, and "El Niño" and "La Niña" (positive phase of El Niño) events (Andrade and Barton, 2001).

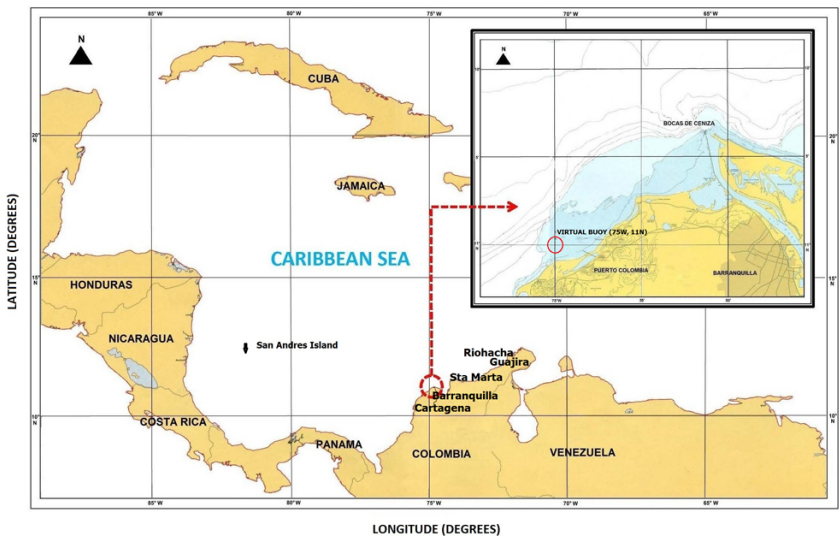

Fig. 4. Caribbean Sea (Source: CIOH-DIMAR).

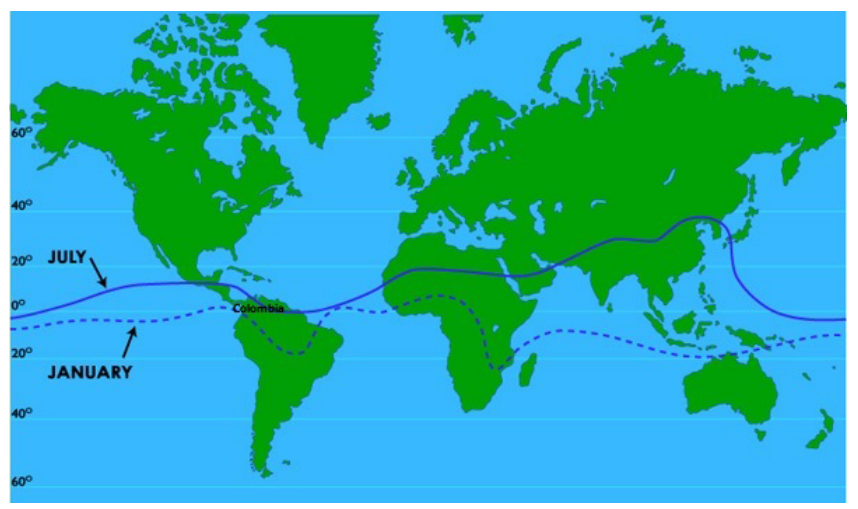

Fig. 5. Intertropical Convergence Zone in July and January.

When the winds of the San Andrés jet are stronger, the dry season occurs throughout the Caribbean coast, which coincides with intense NE trade winds. The same process occurs for the "Veranillo de San Juan". In contrast, the wet season coincides with the period of the greatest intensity of the Chocó jet winds and a lower intensity of the San Andrés jet winds. Throughout the entire Caribbean coast, the wettest month of the year is October, and the driest months are February and March; however, there is a strong spatial variation of this parameter.

The mean temperature in the area, obtained as a multiyear average for data from airport meteorological stations, is approximately $27.6^{\circ} \mathrm{C}$, and the relative humidity of the study area is approximately $82.4 \%$ (Fig. 6).

\section{Methodology}

Using weather information developed by the $\mathrm{CIOH}$ and IDEAM, all cold front reported events between 1996 and 2012 were identified. In a monthly marine-weather bulletin, the $\mathrm{CIOH}$ reports all climate patterns in the Colombian Caribbean for each month as well as the characteristic events and most relevant phenomena that occur in marine 

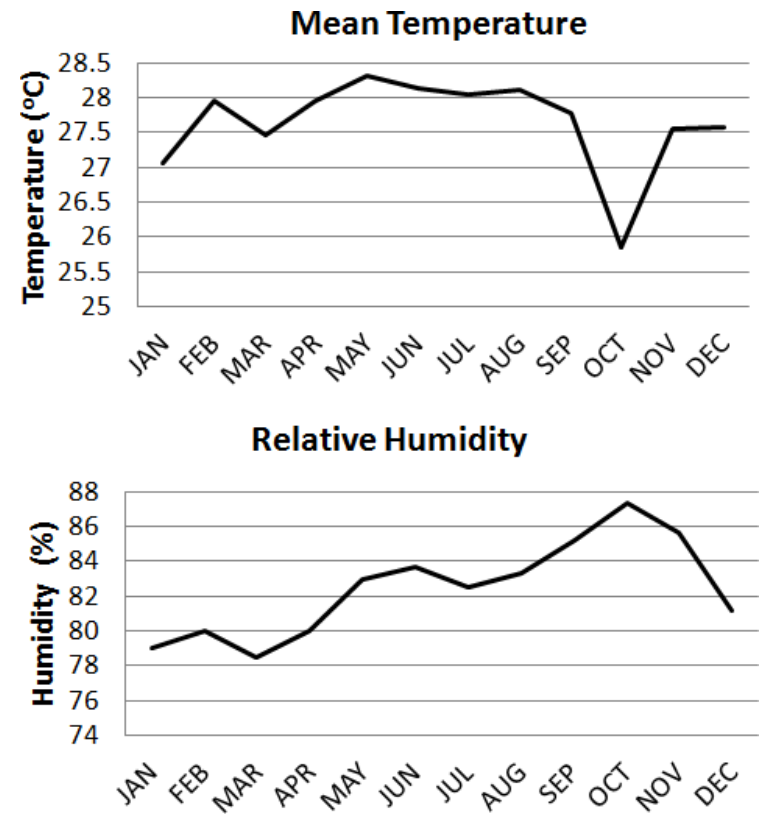

Fig. 6. Mean temperature and mean relative humidity of the Colombian Caribbean zone (Ortiz and Rosales, 2012).

and shoreline zones of the coasts and islands comprising this zone. These reports were reviewed, month by month, and the reported oceanic-atmospheric phenomena were classified. The phenomena associated with the passage of cold fronts through the Caribbean Sea and their relationship to the extreme wave heights in this region were also reported. Cold fronts that initiated an entry into the Gulf of Mexico but that became occluded or disappeared before moving completely into the waters of the Caribbean Sea were excluded. The events that were finally selected were organized monthly for each year that was reviewed. With this information, annual and multiannual characterizations were performed to establish the seasonality and trends associated with the passage of these fronts in the Colombian Caribbean as well as their relationship to the generation of extreme waves.

For the wave analysis, historical data (1996-2012) were obtained from a virtual buoy near the Colombian Caribbean coast (red circle in Fig. 3), located at coordinates $75^{\circ} \mathrm{W}$ and $11^{\circ} \mathrm{N}$. The data were extracted from the wave propagation model of NOAA called WAVEWATCH III, or WW3, which was created by Tolman (1991). These buoys simulate wave parameters, such as the significant height $\left(H_{\mathrm{s}}\right)$, peak period $\left(T_{\mathrm{p}}\right)$, and mean wave direction (MWD), as well as regional model results of WW3, as run in the Caribbean with a spatial resolution of $0.25^{\circ} \times 0.25^{\circ}$ and showing results every $3 \mathrm{~h}$.

A continuous wavelet transform (CWT) was applied to this series to identify periodicities and patterns of interannual variability in the significant height $\left(H_{\mathrm{S}}\right)$ data simulated by the virtual buoy. CWT analysis provides significant advantages over more traditional methods (e.g., fast Fourier transform) because it allows for the location of frequency signals within a time scale (Torrence and Compo, 1998). The CWT $\left(W_{n}\right)$ of a discrete sequence $x_{n}$ is defined as the convolution of $x_{n}$ with a scaled and translated version of $\psi_{o}(\eta)$ (Torrence and Compo, 1998):

$W_{n}(s)=\sum_{n^{\prime}}^{N-1} x_{n^{\prime}} \psi *\left[\frac{\left(n^{\prime}-n\right) \delta t}{s}\right]$,

where $*$ indicates the complex conjugate, $\delta t$ represents the temporal resolution of the discrete series, and $\psi$ corresponds to the parent function (i.e., Paul, Morlet, Mexican Hat). The latter is usually a normalized Morlet wavelet, defined as:

$\psi_{o}(\eta)=\pi^{-1 / 4} e^{i \varpi_{o} \eta} e^{-\eta^{2} / 2}$,

where the subscript $o$ indicates that $\psi$ must be normalized, $\omega_{o}$ is the non-dimensional frequency, and $\eta$ is a dimensionless time parameter. To approximate the CWT, the convolution given in Eq. (1) must be performed $N$ times for each scale, where $N$ is the number of points in the time series. After selecting $N$ points, the convolution theorem allows for the simultaneous performance of $N$ convolutions in Fourier space using a discrete Fourier transform for $x_{n}$ :

$\wedge x_{k}=\frac{1}{N} \sum_{n=0}^{N-1} x_{n} e^{-2 \pi i k n / N}$,

where $k=0 \ldots N-1$ is the frequency index. According to the convolution theorem, the wavelet transform is the inverse of the Fourier transform of the product:

$W_{n}(s)=\sum_{k=0}^{N-1} \wedge x_{k} \wedge \psi *\left(s \varpi_{k}\right) e^{i \omega_{k} n \delta t}$,

where the angular frequency is defined as:

$\varpi_{k}= \begin{cases}\frac{2 \pi k}{N \delta t} & k \leq \frac{N}{2} \\ -\frac{2 \pi k}{N \delta t} & k>\frac{N}{2} .\end{cases}$

Using Eq. (4) and a Fourier transform numerical subroutine, it is possible to simultaneously calculate the CWT for all $n$ (Torrence and Compo, 1998). One advantage of the wavelet transform is that it is independent of the scale, which is useful for analyzing time series containing non-stationary functions at different frequencies, thereby helping to reveal aspects such as trends, break points, and discontinuities in a continuous and discrete time series. For this reason, wavelet analysis has been used successfully in detecting periodicities in geophysical data sets (e.g., Gamage and Blumen, 1993; Liu, 1994; Mak, 1995; Torrence and Compo, 1998; Labat, 2005; Labat et al., 2005; Pasquini and Depetris, 2007). 


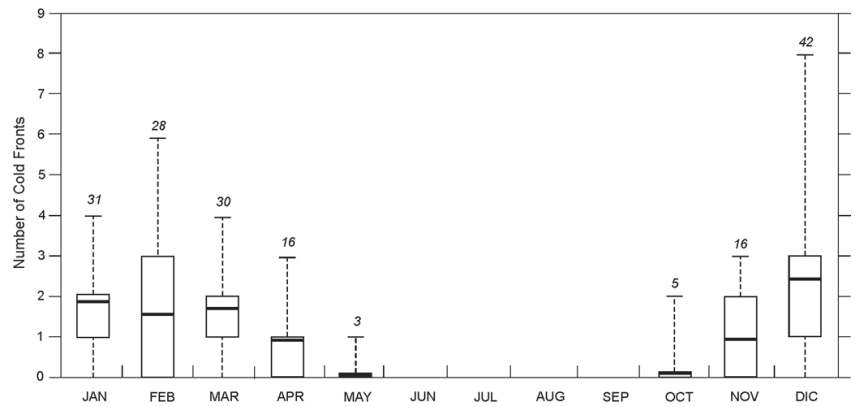

Fig. 7. Seasonal variation (box plot) of the number of cold fronts; values were estimated using data from 1996 to 2012.

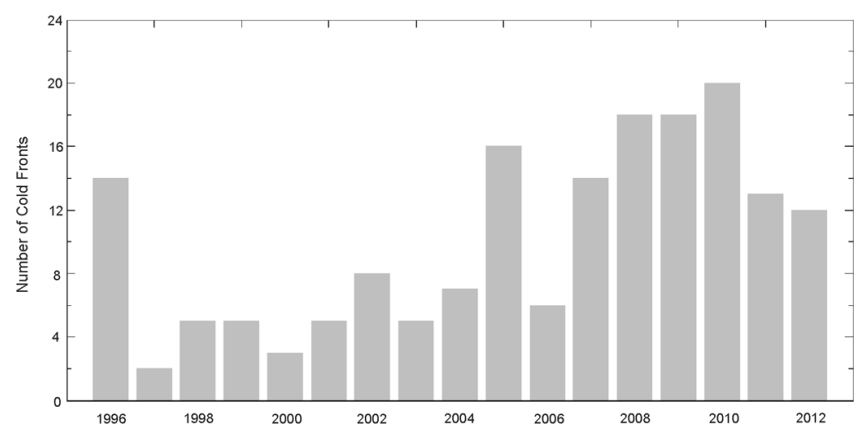

Fig. 8. Annual variation of the number of cold fronts; values were estimated using data from 1996 to 2012.

\section{Results and discussion}

\subsection{Cold fronts}

The seasonal variation of the occurrence of cold fronts in the Colombian Caribbean is shown in Fig. 7. The box plot is a graphical representation of data that shows a data set's lowest value, highest value, median value, and the size of the first and third quartile. The box plot is useful in analyzing small data sets that do not lend themselves easily to histograms. Because of the small size of a box plot, it is easy to display and compare several box plots in a small space.

On average, six cold fronts occur annually in the area. There is an observable trend over the last $16 \mathrm{yr}$, although the maximum number of events, a total of 20 , occurred in 2010. There were a minimum number of cold fronts in 1997, with three events in the study area. The season with the highest number of registered cold fronts (2010) coincided with a rapid transition from the warm phase of the ENSO (May 2009-March 2010), characterized by moderate negative anomalies in the Southern Oscillation Index $(-2<$ SOI $<0)$, to a cold phase (April 2010-April 2011), in which strong positive anomalies of this index were observed $(\mathrm{SOI}>3)$. Figure 8 shows the annual variation in the occurrence of cold fronts in the Caribbean (1996-2012).

As shown in Fig. 7, the atmospheric disturbances are concentrated in the dry season, i.e., from December to May.

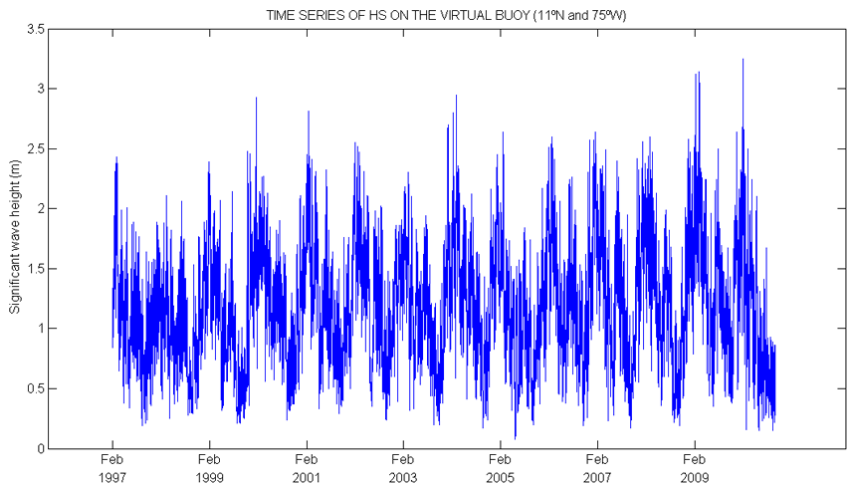

Fig. 9. Significant wave height of the virtual buoy.

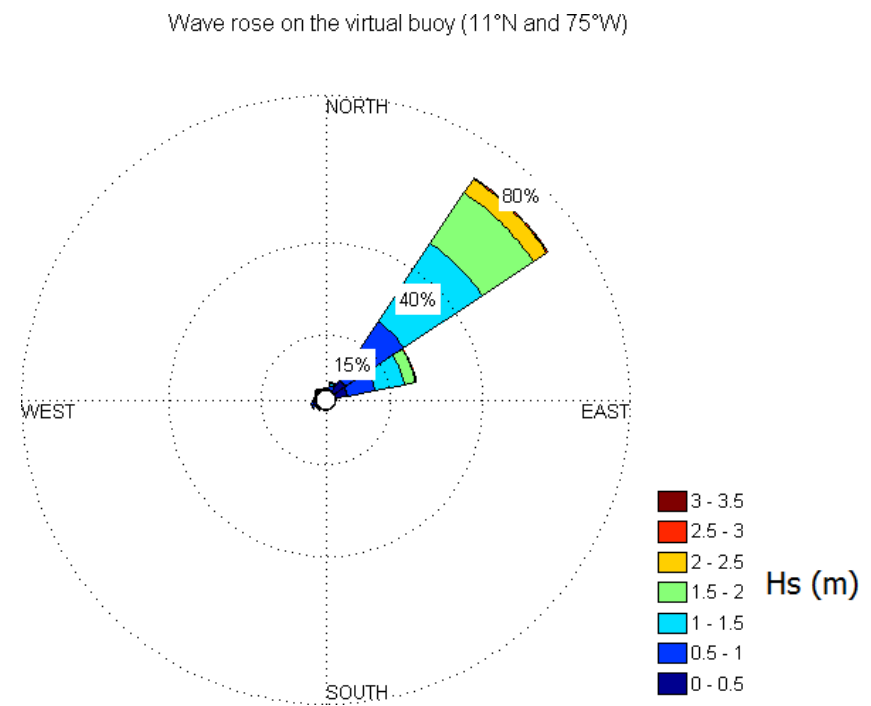

Fig. 10. Wave rose of the virtual buoy.

The greatest numbers of cold fronts have occurred in January and February, and $64 \%$ of cold fronts occur in the first three months of the year. There were no cold fronts during the months of June, July, August, and September. June and July represent the so-called transition period, or "Veranillo de San Juan", and mark the beginning of the wet season for the Colombian Caribbean. The beginning of the cold front season occurs immediately following the end of the wet season (October), with a minimum number of events occurring in October and a peak in February.

\subsection{Waves}

The $H_{\mathrm{s}}$ time series $\left(H_{\mathrm{s}}\right.$ is called the significant wave height in meters, corresponding to the average of the highest one third of the waves) and the wave rose plot based on data from the virtual buoy used in this study are shown in Figs. 9 and 10, respectively. Figures 11 and 12 show the monthly and multiyear averaged significant wave heights, respectively. 


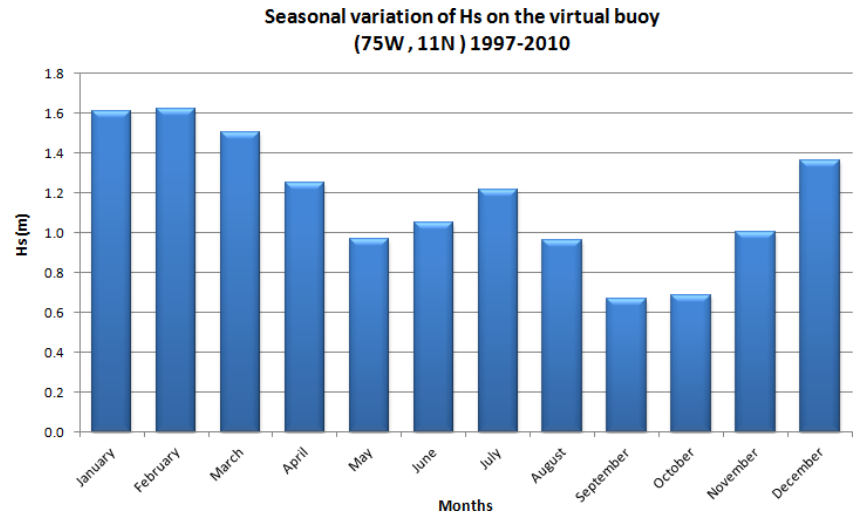

Fig. 11. Seasonal variation of the significant wave height of the virtual buoy.

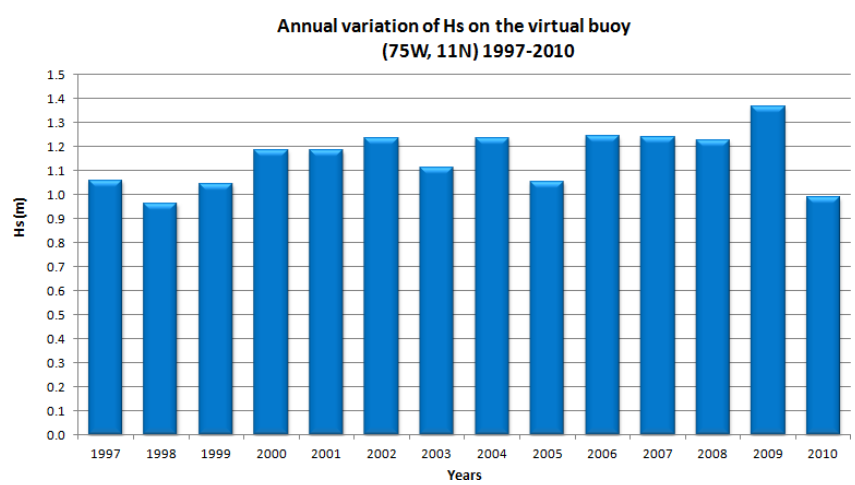

Fig. 12. Annual variation of the significant wave height of the virtual buoy.

As shown in Figs. 10 and 11, on average, higher $H_{\mathrm{S}}$ values correspond to the first three months of the year, which occur in the peak cold front occurrence in the area as well as the increase in the trade winds from the east. In contrast, during the Caribbean hurricane season, the average $H_{\mathrm{s}}$ value is lower. The annual variation of $H_{\mathrm{s}}$ does not exhibit any significant trend for the last $16 \mathrm{yr}$. The average value ranges from 1.2 to $1.5 \mathrm{~m}$.

The maximum $H_{\mathrm{s}}$ values from the virtual buoy time series are presented in Fig. 13. These data clearly indicate that the highest $H_{\mathrm{s}}$ values of the series correspond to the passage of cold fronts in the area, as was reported in the IDEAM and $\mathrm{CIOH}$ marine-weather bulletins (grey bar); the black bar shows the maximum height associated with the passage of the cold front in March 2009, which resulted in the collapse of the Puerto Colombia pier, as described by Ortiz et al. (2012). A photograph taken two hours after the collapse of the structure is presented in Fig. 14.

The CWT was applied to the significant wave height data from the NOAA virtual buoy (Fig. 9). This analysis allows for the differentiation between the temporal fluctuations of a time series, thereby identifying the intermittence of each of the processes at a specific temporal scale (Fig. 15). White

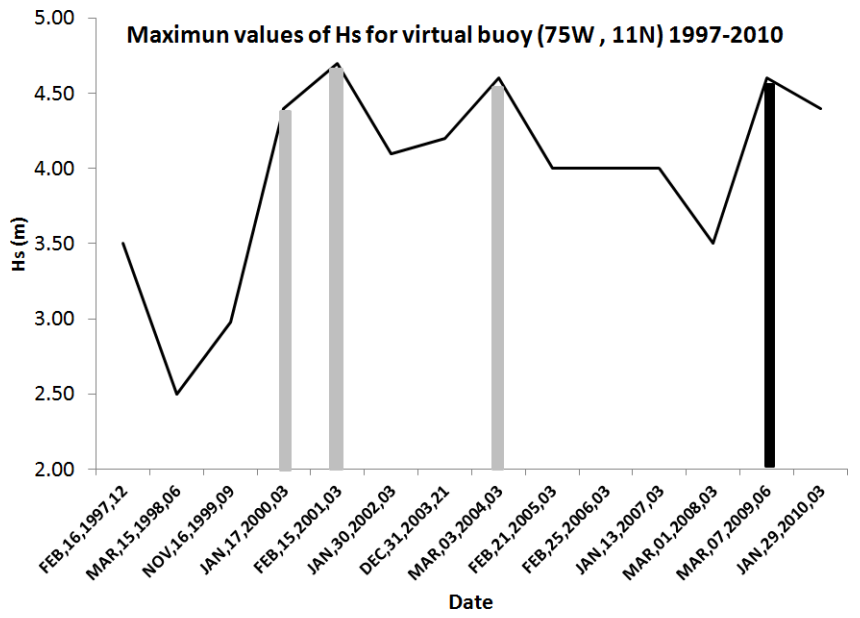

Fig. 13. Maximum values of the significant wave height of the virtual buoy.

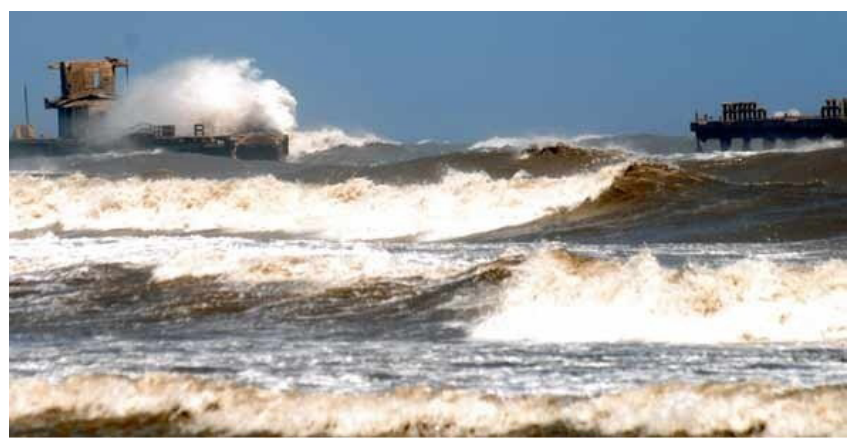

Fig. 14. Extreme waves due to the cold front that passed in March 2009 (Ortiz et al., 2012).

and lighter colors in the wavelet spectra correspond to high values of the transform coefficients (power). The thick black contour delimits the $95 \%$ confidence level against AR (1) red noise and the cone of influence where edge effects $(T / 2 \sqrt{ } 2)$ are not negligible is shown as a black thin line (Fig. 15). The wavelet analysis shows that processes with scales of less than six months are highly intermittent and scattered. In contrast, the annual and semi-annual signals appear quasi-stationary and of a consistent magnitude (i.e., power) over the entire recording period. Inter-annual fluctuations of the significant wave height are characterized by intermittent processes at a quasi-biennial scale ( $\sim 18$ to 36 months). The wavelet spectrum highlighted the signal of the band of 18 months during 1998-2001 and 2007-2010 as well as the signal of the band of 36 months during 1997-1999, 2003, and 2008-2010 (Fig. 15). There is a clear period of intense activity between 2008 and 2010, wherein oscillations occur at semi-annual, annual, and quasi-biennial scales, which coincides with years when the greatest significant heights (Fig. 12) and the highest number of cold fronts were recorded (Fig. 8). 


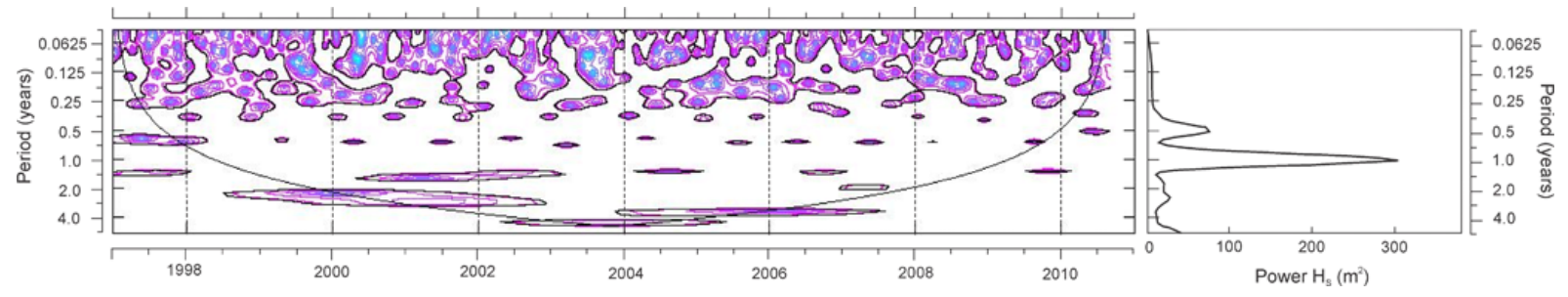

Fig. 15. Continuous wavelet transform spectrum (left) and global wavelet spectrum (right) for $H_{\mathrm{s}}$ of the virtual buoy.

The continuous wavelet spectrum was averaged over time to quantify the dominant scales within the processes of variability, allowing for the determination of the distribution of the signal variance between different time scales (Torrence and Compo, 1998). Accordingly, this integration technique generates a comprehensive wavelet spectrum (Fig. 15).

The white and lighter colors in the wavelet spectra in Fig. 15 correspond to high values of the transform coefficients (power), the thick black contour delimits the $95 \%$ confidence level against AR(1) red noise, and the cone of influence where edge effects $(T / 2 \sqrt{ } 2)$ are not negligible is shown as a thin black line. For the virtual buoy, the annual band appears as the main oscillatory component, whereas the semiannual band (0.5 annual) emerges as the source of second order in the variability of the significant wave height.

\section{Conclusions}

In this study, cold fronts occurring in the Colombian Caribbean during the past $16 \mathrm{yr}$ were characterized. A strong seasonality of cold fronts in this region was established, with cold fronts occurring most often during the first three months of the year (January, February, and March), and there were approximately six fronts per year on average in the Colombian Caribbean. The year 2010 saw the highest number of events, with 20 fronts occurring in the region. The period with the greatest number of cold fronts recorded coincided with a rapid transition from the warm phase of the ENSO phenomenon to a cold phase in which there were strong positive anomalies in the SOI. This trend indicates the need for a greater understanding of these relationships to establish connections between the variability and magnitude of cold fronts and the dynamics of large-scale atmospheric-oceanographic oscillations (e.g., the El Niño-South Oscillation, North Atlantic Oscillation, Pacific Decadal Oscillation, and Tropical North Atlantic Index).

According to the analysis of the virtual buoy data from the NOAA spectral wave model, there was an increase in the average value of $H_{\mathrm{S}}$ during the first three months of the year. The series of maximum $H_{\mathrm{s}}$ values for this region indicates that extreme wave events during the last 16 yr were produced by cold fronts, as reported in meteorological-marine bulletins.
Wavelet analysis showed that processes at scales of less than six months are highly intermittent and scattered. By contrast, interannual fluctuations in the significant wave height are characterized by intermittent processes occurring at a quasi-biennial scale. Additionally, a period of intense activity was identified between 2008 and 2010. During this period, oscillations occurred at semi-annual, annual, and quasibiennial scales, and the greatest significant heights and the largest number of cold fronts were recorded.

Although the Colombian Caribbean has been affected by storms and hurricanes in the past, this research allows us to conclude that cold fronts have had a strong relationship to the largest waves in the Colombian Caribbean during the last $16 \mathrm{yr}$, which have caused damage to coastal infrastructure. We confirmed that the most significant extreme wave event of the last two decades in the Colombian Caribbean, which led to the structural collapse of Puerto Colombia pier, near the city of Barranquilla, corresponded to the passage of a cold front between 5 and 10 March 2009. This information could be important when assessing the average and extreme wave regimes for the purpose of aiding the design of structures in this area of the Caribbean.

Acknowledgements. We thank to The Administrative Department of Science, Technology and Innovations of Colombia (COLCIENCIAS) for their financing, the Office of Research and Projects (DIDI) at the Universidad del Norte, Instituto de Hidrología, Meteorología y Estudios Ambientales (Institute of Hydrology, Meteorology and Environmental Studies of Colombia) (IDEAM) of Colombia and El Centro de Investigación Oceanográfico e Hidrográfico de la Armada Nacional de Colombia (Oceanographic and Hydrographic Research Center of the Colombian Navy) (CIOH).

Edited by: R. Lasaponara

Reviewed by: three anonymous referees

\section{References}

Andrade, C. and Barton, E.: Eddy development and motion in the Caribbean Sea. J. Geo. Res., 105, 26191-26201, 2001.

Beringer, J. and Tepper, N.: The influence of subtropical cold fronts on the surface energy balance of a semi-arid site, J. Arid Environ., 44, 437-450, doi:10.1006/jare.1999.0608, 2000. 
Decibel, V., Graciano, F.-E., Yumul Jr., P., Servando, N. T., and Dimalanta, C. B.: The January 2009 anomalous precipitation associated with the "Tail-end of the Cold Front" weather system in Northern and Eastern Mindanao (Philippines), Natural Hazards, impacts and risk reductions, Global Planet. Change, 76, 85-94, 2011.

Gamage, N. and Blumen, W.: Comparative analysis of low-level cold fronts: Wavelet, Fourier, and empirical orthogonal function decompositions, Mon. Weather Rev., 121, 2867-2878, 1993.

Hastenrath, S.: Climate Dynamics of the Tropics, Atmospheric Sciences Library, Kluwer Academic Publishers, Netherlands, 1991.

Labat, D.: Recent advances in wavelet analyses: Part: 1 - A review of concepts, J. Hydrol., 314, 275-288, 2005.

Labat, D., Ronchall, J., and Guyot, J. L.: Recent advances in wavelet analyses: Part: 2 - Amazon, Parana, Orinoco and Congo discharges time scale variability, J. Hydrol., 314, 289-311, 2005.

Liu, P. C.: Wavelet spectrum analysis and ocean wind waves, in: Wavelets in Geophysics, edited by: Foufoula, E. and Kumar, P., Academic Press, 151-166, 1994.

Locatelli, J. D., Sienkiewicz, J. M., and Hobbs, P. V.: Organization and structure of clouds and precipitation on the mid-Atlantic coast of the United States. Part I: Synoptic evolution of a frontal system from the Rockies to the Atlantic Coast, J. Atmos. Sci., 46, 1327-1348, 1989.

Mak, M.: Orthogonal wavelet analysis: interannual variability in the sea surface temperature, Bull. Am. Meteorol. Soc., 76, 21792186, 1995.

Mayhew, S.: A dictionary of Geography, available at: www.xrefer. com/entry/609388 (last access: 24 January 2013), Oxford University Press, 1997.
Namías, J.: Introduction to the study of air masses, s.p.i., 1960.

Narváez, G. and León, G.: Intrusion of cold air in tropical areas - case study from January 5 to January 8, 2002, Meteorol. Colomb., 7, 99-108, ISSN 0124-6984, Bogotá, D.C. - Colombia, 2003.

Ortiz, J. C.: Exposure of the Colombian Caribbean Coast, including San Andrés Island, to Tropical Storms and Hurricanes, 19002010, Nat. Hazard J., 61, 815-827, 2012.

Ortiz, J. C. and Rosales, M.: Severe Tornadoes on the Caribbean Coast of Colombia Since 2001 and Their Relation to Local Climate Conditions, Nat. Hazard J., 64, 1805-1821, 2012.

Ortiz, J. C., Salcedo, B., and Otero, L.: Investigating the collapse of the Puerto Colombia Pier (Colombian Caribbean Coast) in March of 2009: methodology for the reconstruction of extreme events and their impact on the coastal infrastructure, JCOASTRES-D-12-000621, 2012.

Pasquini, A. and Depetris, P.: Discharge trends and flow dynamics of south American rivers draining the southern Atlantic seaboard: An overview, J. Hydrol., 333, 385-399, 2007.

Thompson, R: Atmospheric Processes and Systems, London, Routledge, 1998.

Tolman, H. L.: A third-generation model for wind waves on slowly varying, unsteady and inhomogeneous depths and currents, J. Phys. Oceanogr., 21, 782-797, 1991.

Torrence, C. and Compo, G.: A practical guide to wavelet analysis, Bull. Am. Meteorol. Soc., 79, 61-78, 1998.

Zhixuan, F. and Chunyan, L. Cold-front-induced flushing of the Louisiana Bays, J. Mar. Syst., 82, 252-264, 2010. 